\title{
Specific Phobia
}

National Cancer Institute

\section{Source}

National Cancer Institute. Specific Phobia. NCI Thesaurus. Code C35284.

An anxiety disorder characterized by an intense, irrational fear cued by the presence or anticipation of a specific object or situation. Exposure to the phobic stimulus immediately provokes an anxiety response. In adults, the specific phobia is recognized as excessive or unreasonable. 